\title{
Fungos endofíticos associados a acículas de Pinus taeda
}

\author{
Ida Chapaval Pimentel ${ }^{1 *}$, Gisele Figura ${ }^{1}$, Celso Garcia Auer ${ }^{2}$
}

${ }^{1}$ Departamento de Patologia Básica, Universidade Federal do Paraná, CEP 81531-990, Curitiba, PR; ${ }^{2}$ Embrapa Florestas, C.P. 319, CEP 83411000, Colombo, PR.

Autor para correspondência: Ida Chapaval Pimentel (ida@ufpr.br)

Data de chegada: 31/10/2008. Aceito para publicação em: 31/08/2009.

\section{RESUMO}

Pimentel, I. C.; Figura, G.; Auer, C. G. Fungos endofíticos associados a acículas de Pinus taeda. Summa Phytopathologica, v.36, n.1, p.xx-xx, 2010 .

O presente trabalho objetivou estudar os fungos endofíticos em acículas de árvores jovens de Pinus taeda L. e avaliar o efeito da posição de coleta na árvore. As amostras foram coletadas em duas alturas (30-50 cm e 100-130 cm acima do solo) e nas quatro posições cardeais (norte, sul, leste e oeste), em plantas com 18 meses de idade, localizadas em Colombo, PR, Brasil. As acículas foram submetidas a assepsia e fragmentos com $10 \mathrm{~mm}$ de comprimento foram plaqueados em meio BDA e incubados a $28{ }^{\circ} \mathrm{C}$, sob fotofase de $12 \mathrm{~h}$, por 15 dias. Para a identificação, as estruturas reprodutivas dos fungos foram produzidas pelo método do microcultivo. Foram isolados e identificados dezessete gêneros: Alternaria, Aspergillus, Cladosporium, Colletotrichum, Coniothyrium, Diplodia, Drechslera, Hansfordia, Monocillium, Nodulisporium, Panidio, Papulaspora, Pestalotiopsis, Phialophora, Pithomyces, Rhizoctonia e Xylaria Alguns morfotipos sem identificação foram Mycelia sterilia e fungos demaciáceos. O número de isolados da altura $30-50 \mathrm{~cm}$ foi significativamente maior que na outra altura. Não foi observada diferença significativa no número de isolados entre as posições cardeais de uma mesma altura. Diferenças significativas foram observadas entre os gêneros isolados e Xylaria foi o gênero mais frequente.

Palavras-chave adicionais: filoplano, floresta, microrganismos, pínus.

\section{ABSTRACT}

Pimentel, I. C.; Figura, G.; Auer, C. G. Endophytic fungi associated to Pinus taeda needles. Summa Phytopathologica, v.36, n.1, p.xx-xx, 2010.

The present work aimed to study the endophytic fungi in Pinus taeda needles and to evaluate the effect of sample points in the tree. Samples were collectd in two different heights (30-50 cm and 100-130 $\mathrm{cm}$ over ground) and cardinal positions (North, South, East and West) in plants with 18 months old, located at Colombo, PR, Brazil. The needles were sucessively washed in sterile destilled water, $70 \%$ ethanol, $\mathrm{NaHClO} 3 \%, 70 \%$ ethanol and sterile destilled water. Needle fragments of $10 \mathrm{~mm}$ of lenth were plated in PDA medium, incubated at $28{ }^{\circ} \mathrm{C}$, fotophase $12 \mathrm{~h}$ to 15 days. The reproductive structures of fungi were produced by microculture technique. Seventeen genera were identified: Alternaria, Aspergillus, Cladosporium, Colletotrichum, Coniothyrium, Diplodia, Drechslera, Hansfordia, Monocillium, Nodulisporium, Panidio, Papulaspora, Pestalotiopsis, Phialophora, Pithomyces, Rhizoctonia and Xylaria. Some non identified morphotypes were Mycelia sterilia and dematiaceous fungi. The number of isolates from the $30-50 \mathrm{~cm}$ height was significantly higher than the other. No differences were observed on number of isolates among cardinal positions at the same height. It was observed significant differences were observed among the isolated genera and Xylaria was the most frequent genus.

Keywords: forest, microorganisms, phyloplane, pine.

Espécies de Pinus foram introduzidas no Brasil há mais de um século, trazidas pelos imigrantes europeus para fins ornamentais e para a produção de madeira (22). Os primeiros ensaios com espécies européias não obtiveram sucesso, devido a falta de adaptação ao clima brasileiro. Em 1948, foram introduzidas as espécies norte-americanas conhecidas como "pinheiros amarelos", dentre as quais destacaram-se Pinus elliottii var. elliottii e Pinus taeda (22) que são as mais plantadas no Brasil.

A ocorrência de fungos em folhas assintomáticas é comumente relatada, sugerindo que alguns microrganismos podem colonizar os órgãos das plantas sem o desenvolvimento de sintomas de doença. Tais microrganismos receberam a denominação de fungos endofíticos ou endófitos (19). Sabe-se que os endofíticos são importantes e podem produzir toxinas, antibióticos e outros fármacos, fatores de crescimento e muitos produtos de interesse biotecnológico (4).

As espécies de fungo envolvidas podem variar de acordo com o hospedeiro, distribuição geográfica, idade da planta, condições ecológicas e sazonais, incluindo-se a altitude e precipitação. Uma ou duas espécies podem ser dominantes como endofíticas em determinado hospedeiro, enquanto outros isolados são pouco frequentes $(2,4,6)$

Na literatura científica são escassos relatos sobre fungos endofíticos em acículas de Pinus, envolvendo espécies de pínus não utilizadas em plantios no Brasil. Para o estado do Paraná não existem estudos para verificação da população de endofíticos colonizando acículas de $P$. taeda, a espécie mais representativa em termos de áreas de reflorestamento na região Sul do Brasil. Assim, o presente estudo objetivou realizar uma avaliação da população dos fungos endófitos presentes em acículas de $P$. taeda e coletadas em duas diferentes 
posições na planta.

Por ser um estudo exploratório, três árvores de P. taeda com 18 meses de idade foram amostradas em duas alturas em relação ao solo (30-50 cm e 100-130 cm) e nas posições cardeais Norte, Sul, Leste e Oeste. As árvores estavam situadas em um plantio experimental da Embrapa Florestas localizada a $25^{\circ} 20^{\prime} \mathrm{S}$ e $49^{\circ} 14^{\prime} \mathrm{W}$, com altitude média de $920 \mathrm{~m}$. O clima é temperado sempre úmido, do tipo $\mathrm{Cfb}$, segundo a classificação de Köppen. Essa área apresenta solos tipo HO1 (orgânicos álicos fase campestre subtropical, relevo plano) + tipo PV1 (Podzólicos Vermelho Amarelo, textura argilosa, relevo forte ondulado) + CA8 (associação cambisol álico e rubrozem, relevo suave ondulado) (16). As acículas foram coletadas pela manhã antes do sol incidir sobre as plantas, e colocadas em sacos de polietileno e identificadas.

No laboratório, as acículas coletadas foram lavadas em água corrente, tomando-se o devido cuidado para não se provocar ferimentos. A desinfestação da superfície das acículas consistiu em uma sequência de imersão das amostras por duas vezes em água destilada esterilizada, um minuto em etanol $70 \%$, cinco minutos em hipoclorito de sódio $3 \%$, trinta segundos em etanol $70 \%$ e finalmente lavadas três vezes em água destilada esterilizada. Dez acículas foram selecionadas ao acaso, de cada amostra, e assepticamente cortadas em cinco fragmentos com aproximadamente $10 \mathrm{~mm}$, totalizando 1.200 fragmentos (excluindo-se sempre as partes distais). Na sequência, os fragmentos foram transferidos para placas de Petri contendo meio batata-dextrose-ágar - BDA (extrato comercial de batata e dextrose, 39 g; água destilada $1000 \mathrm{~mL}$ ). Para cada amostra, foram preparadas 20 placas com cinco fragmentos. Também, foram preparadas placascontrole contendo $0,1 \mathrm{~mL}$ da última água destilada esterilizada utilizada na lavagem, para verificação da presença de contaminantes epifíticos, de acordo com Petrini (18). As placas foram mantidas a $28 \pm{ }^{\circ} \mathrm{C} \mathrm{em}$ câmara BOD, com fotoperíodo de 12 horas durante 15 dias, sendo observadas diariamente para verificação da formação de colônias. Logo após o início do crescimento dos fungos nas placas, pequenos fragmentos do ágar contendo pontas de hifas de fungos foram transferidos para tubos de ensaio contendo meio BDA inclinado. Os tubos foram mantidos a $28 \pm 1{ }^{\circ} \mathrm{C}$ e, após o crescimento das colônias, mantidos em refrigerador a $4{ }^{\circ} \mathrm{C}$.

Os isolados obtidos foram agrupados em morfotipos de acordo com as similaridades e aspectos da morfologia da colônia fúngica. Para a observação das estruturas reprodutivas utilizou-se a técnica do método de cultura em lâmina ou microcultivo (13). As estruturas foram coradas com lactofenol de Amann e analisadas ao microscópio ótico. A identificação dos isolados foi realizada de acordo com a literatura especializada $(1,3,5,7,8,11,14,15,18,20)$ e as colônias de fungos não identificadas foram denominadas como N.I. (não identificadas).

O número total de isolados de fungos endofíticos e o número de isolados de gêneros de fungos em acículas de $P$. taeda nas duas alturas: $30-50$ cm e $100-130 \mathrm{~cm}$, a comparação da frequiência de cada gênero, considerando oito tratamentos (posições norte, sul, leste e oeste nas duas alturas amostradas) foram as variáveis analisadas. Os dados foram analisados num esquema fatorial, transformados para $\log (x+2)$, submetidos à análise de variância (ANOVA) e as médias comparadas por meio de teste de Tukey ao nível de $5 \%$ de probabilidade, utilizando o software ASSISTAT versão 7.5 (23).

A partir dos 1.200 fragmentos de acículas de P. taeda, foram isolados 784 fungos endofíticos, sendo 460 isolados na altura $30 \mathrm{~cm}-50 \mathrm{~cm}$ e 324 na altura $100 \mathrm{~cm}-130 \mathrm{~cm}$ (Tabela 1). Quando avaliado o número total de fungos endofíticos, valores do teste $\mathrm{F}$ significativos foram encontrados somente entre as diferentes alturas e na interação altura $\mathrm{x}$
Tabela 1. Número total de colônias de fungos endofíticos isolados de acículas de Pinus taeda em função da posição de coleta na planta e altura em relação ao solo.

\begin{tabular}{llllll}
\hline \multirow{2}{*}{ Altura da coleta } & \multicolumn{4}{c}{ Posição cardeal } & \multicolumn{2}{c}{ Total } \\
& Norte & Sul & Leste & Oeste & \\
\hline $30 \mathrm{~cm}-50 \mathrm{~cm}$ & $106 \mathrm{Aa}$ & $121 \mathrm{Aa}$ & $100 \mathrm{Aa}$ & $133 \mathrm{Aa}$ & $460 \mathrm{x}$ \\
$100 \mathrm{~cm}-130 \mathrm{~cm}$ & $81 \mathrm{Aa}$ & $71 \mathrm{Aa}$ & $108 \mathrm{Aa}$ & $64 \mathrm{Ab}$ & $324 \mathrm{y}$ \\
Total & $187 \mathrm{X}$ & $192 \mathrm{X}$ & $208 \mathrm{X}$ & $197 \mathrm{X}$ & 784 \\
\hline
\end{tabular}

$\mathrm{CV}=28,3 \%$. Valores seguidos por letras distintas, nas linhas (maiúsculas) e colunas (minúsculas), diferem entre si (Tukey $5 \%$ )

posição. Quando comparadas às médias, verificou-se diferenças significativas entre as posições sul e oeste quando comparadas as duas alturas e as médias das posições norte e leste não diferiram estatisticamente entre si. Não foi observada diferença significativa entre as diferentes posições cardeais de uma mesma altura.

No presente trabalho verificou-se aumento no número de espécies isoladas em função do tipo de acícula coletada e do local na planta, onde se observou maior frequência de fungos colhidas na altura de 30 $\mathrm{cm}-50 \mathrm{~cm}$ (acículas mais velhas) quando comparada com a frequência na altura de $100 \mathrm{~cm}-130 \mathrm{~cm}$. Estudos com a caracterização de fungos endofíticos em folhas sadias de Nicotiana spp. (24), em condições de campo, mostraram que o número de endófitos aumentou significativamente com o desenvolvimento das folhas. Pereira et al. (17) relataram uma relação direta entre a frequência de infecção das folhas e a idade das plantas. Sabe-se que a idade da planta e os órgãos utilizados interferem no número e tipos de microrganismos isolados (4).

Fisher et al. (10) isolaram 23 gêneros de endofiticos de quatro plantas de Opuntia stricta crescendo em quatro localidades da Austrália, sendo a maioria constituída de gêneros de fungos com ampla distribuição e em grande número de hospedeiros. A posição de amostragem avaliada nas plantas de $O$. stricta e o seu estádio fenológico aparentemente determinaram o grau de colonização. Esses autores também relataram que a frequência de colonização do endofítico pode ser dependente da disponibilidade do inóculo e da posição do tecido da planta, muito mais do que da localização geográfica das plantas. No presente estudo, não foram observadas diferenças significativas quando comparadas as diferentes posições em relação à frequiência total de fungos endofíticos isolados.

Dezessete gêneros de fungos foram encontrados, independentemente da amostragem: Alternaria, Aspergillus, Cladosporium, Colletotrichum, Coniothyrium, Diplodia, Drechslera, Hansfordia, Monocillium, Nodulisporium, Panidio, Papulaspora, Pestalotiopsis, Phialophora, Pithomyces, Rhizoctonia, Xylaria. Os fungos isolados que apresentavam somente micélio escuro estéril (fungos demaciáceos) não foram classificados ao nível de gênero. Alguns isolados não produziram estruturas reprodutivas (Mycelia sterilia). Em relação ao total de fungos endofíticos de cada gênero encontrados, houve diferenças significativas para todas as posições amostradas.

$\mathrm{Na}$ altura de $30 \mathrm{~cm}-50 \mathrm{~cm}$, o gênero Xylaria foi o mais freqüente diferindo de todos os outros encontrados, em todas as posições cardeais. $\mathrm{Na}$ altura $100 \mathrm{~cm}-130 \mathrm{~cm}$, posição norte, os gêneros Xylaria e Coniothyrium diferiram de todos os demais gêneros e também entre si, com Xylaria sendo o mais frequente. Nas posições sul, leste e oeste observou-se que Xylaria também foi o mais frequente e diferiu de todos os demais gêneros analisados.

Quando da análise separada dos gêneros, com base na frequência total de fungos encontrados em todas as posições de coleta de acículas, 
verificou-se que para o gênero Coniothyrium o valor de F foi significativo para as variáveis altura e posição, e para a interação das duas variáveis. Pode-se afirmar que houve diferenças para o gênero em questão entre as duas alturas da posição oeste, porém nas posições norte, sul e leste esta diferença não foi observada. Entre as posições da altura $30-50 \mathrm{~cm}$, a oeste diferiu significativamente das demais, que apresentaram semelhanças entre si. Entre as posições da segunda altura não foi observada diferença significativa. Os valores de $\mathrm{F}$ foram significativos para a variável altura no gênero Colletotrichum, com frequência significativamente maior de isolados na altura de $30 \mathrm{~cm}-50$ $\mathrm{cm}$. Para o gênero Phialophora, os valores de F foram significativos para as duas variáveis, inclusive para a interação entre altura e posição. Quando comparadas as frequências, observou-se que a posição leste diferiu significativamente das outras posições na altura $100 \mathrm{~cm}-130$ $\mathrm{cm}$, enquanto que não houve diferença estatística entre as demais. A diferença entre as duas alturas foi constatada na posição leste, sendo que as demais não diferem significativamente. Para os gêneros Pithomyces e Xylaria foram encontrados valores significativos de F somente na altura $30 \mathrm{~cm}-50 \mathrm{~cm}$ apresentou valores significativamente maiores que a $100 \mathrm{~cm}-130 \mathrm{~cm}$.

Para os gêneros Alternaria, Cladosporium, Hansfordia, Nodulisporium e Rhizoctonia e fungos demaciáceos e Mycelia sterilia não foram verificadas diferenças significativas.

$\mathrm{O}$ gênero mais frequente nas duas alturas e nas quatro posições foi Xylaria, totalizando 631 colônias $(80,5 \%)$ do total de endofíticos isolados, o qual pode ser chamado de dominante (4). Na sequência os mais frequentes foram Colletotrichum, Pithomyces e Phialophora, com 29, 19 e 14 colônias, respectivamente $(3,7 \%, 2,4 \%$ e 1,8\%). O gênero Alternaria e os fungos demaciáceos apresentaram 10 colônias $(1,3 \%)$. Os demais gêneros tiveram as menores frequências: Mycelia sterilia apresentou seis colônias $(0,8 \%)$, Cladosporium e Nodulisporium totalizaram quatro colônias $(0,5 \%)$, Coniothyrium apresentou três colônias $(0,4 \%)$ e Monocillium, Hansfordia e Rhizoctonia apresentaram duas colônias $(0,3 \%)$ cada. Os gêneros Aspergillus, Diplodia, Drechslera, Panidio, Papulaspora, Pestalotiopsis apresentaram apenas uma colônia $(0,1 \%)$ cada.

Dentre os gêneros citados, Rhizoctonia já foi isolado de Pinus sylvestris (21) e em mudas de Pinus caribaea var. hondurensis e Pinus tecunumanii e híbridos entre essas duas espécies, no estado de São Paulo (9), enquanto que os gêneros Cladosporium, Alternaria e Phialophora foram relatados como endófitos de Pinus ponderosa por Hoff et al. (12).

Nas placas-controle foram observadas 17 colônias, os quais se dividiram em 10 diferentes morfotipos, os quais se supõem serem contaminantes ou epifíticos (Tabela 2). Os seguintes gêneros foram identificados: Cladosporium, Stachybotrys, Phoma, Aureobasidium, Candida, Trichoderma, Mycelia sterilia e fungos dematiáceos. Os gêneros Cladosporium, Mycelia sterilia e fungos dematiáceos já haviam sido encontrados anteriormente, mas os morfotipos diferiram dos que foram considerados endofíticos. Dos diferentes morfotipos

Tabela 2. Número total de colônias de fungos contaminantes (epifíticos) isoladas das placas-controle realizadas com a última água de lavagem das amostras de acículas de Pinus taeda.

\begin{tabular}{|c|c|c|c|c|c|}
\hline \multirow{2}{*}{ Altura da coleta } & \multicolumn{4}{|c|}{ Posição cardeal } & \multirow{2}{*}{ Total } \\
\hline & Norte & Sul & Leste & Oeste & \\
\hline $30 \mathrm{~cm}-50 \mathrm{~cm}$ & 5 & 2 & 3 & 1 & 11 \\
\hline $100 \mathrm{~cm}-130 \mathrm{~cm}$ & 1 & 1 & 2 & 2 & 6 \\
\hline Total & 6 & 3 & 5 & 3 & 17 \\
\hline
\end{tabular}

encontrados, duas colônias não foram identificadas, sendo classificadas como N.I.

Apesar dos fungos endofíticos muitas vezes se apresentarem de forma latente, sem causar sintomas na planta hospedeira, seu estudo é de grande importância. Esses fungos podem produzir substâncias de interesse farmacológico ou serem utilizados para o controle biológico de doenças de plantas (4).

Escassos são os relatos a respeito de fungos endofíticos em $P$. taeda. Assim, considera-se o estudo como pioneiro na investigação e identificação de gêneros endofíticos em acículas de $P$. taeda. Estudos complementares para um melhor entendimento da relação endófito/ hospedeiro dos gêneros encontrados são requeridos.

\section{AGRADECIMENTOS}

Os autores agradecem ao $\mathrm{CNPq}$ pelo apoio financeiro ao projeto de pesquisa.

\section{REFERÊNCIAS BIBLIOGRÁFICAS}

1. Alves, S. B. Controle microbiano de insetos. Piracicaba: FEALQ/USP, 1998. $1163 \mathrm{p}$.

2. Arnold, E. A.; Mejía, C. L.; Kyllo, D.; Rojas, E. I.; Maynard, Z.; Robbins, N.; Herre, E. A. Fungal endophytes limit pathogen damage in a tropical tree. PNAS, Washington, v.100, p. 15649 15654, 2003.

3. Arx, J. A. von. The genera of fungi sporulating in pure culture. 2. ed. Vaduz: J. Cramer, 1974. 351 p.

4. Azevedo, J.L. Microrganismos endofíticos. In: Melo, I.S.; Azevedo, J.L. (Ed.). Ecologia microbiana. Jaguariúna: Embrapa-CNPMA, 1998, p. 117-137.

5. Barnett, H. C.; Hunter, B. B. Illustrated genera of imperfect fungi. 3. ed. Minneapolis: Burgess, 1972. 241p.

6. Carrol, G. C.; Carrol, F. E. Studies on the incidence of coniferous needle endophytes in the Pacific Northwest. Canadian Journal of Botany, Ottawa, v.56, p. 3034-3043, 1978.

7. Ellis, M. B. Dematiaceous hyphomycetes. Kew: Commonwhealth Mycological Institute, 1971. 608 p.

8. Ellis, M. B. More dematiaceous hyphomycetes. Kew: Commonwhealth Mycological Institute, 1976. 507 p.

9. Ferreira, F. A.; Mendes, J. E.; Maia, J. L. Mortalidade de estacas enraizadas de Pinus spp. causada por Rhizoctonia solani. Fitopatologia Brasileira, Fortaleza, v. 30, n. 2, p. 92, 2005.

10. Fisher, P. J.; Sutton, B. C.; Petrini, O. Fungal endophytes from Opuntia stricta: a first report. Nova Hedwigia, Stuttgart, v. 59, n.1/2, p. 195-200, 1994 .

11. Hoog, G. S.; Guarro, J. Atlas of Clinical Fungi. Virgili: Centraalbureau voor Schimelcultures/Universitat rovira i., 2004. 1126 p.

12. Hoff, J. A.; Klopfenstein, N. B.; Mcdonald, G. I.; Tonn, J. R.; Kim, M. S.; Zambino, P. J.; Hessburg, P. J.; Rogers, J. D.; Peever, T. L.; Carris, L. M. Fungal endophytes in woody roots of Douglas-fir (Pseudotsuga menziesii) and ponderosa pine (Pinus ponderosa). Forest Pathology, Berlin, v. 34, n. 4, p. 255-271, 2004

13. Kern, M. E.; Blevins, K. S. Micologia Médica. 2. ed. São Paulo: Editora Premier, 1999. 256 p.

14. Koneman, E. W.; Roberts, G. D. Micologia pratica de laboratório. Buenos Aires: Editorial Médica Panamericana, 1987. 221p

15. Larone, D. H. Medically important fungi: a guide to identification. New York: Elsevier, 1987. 230 p.

16. Oliveira, Y. M. M.; Rotta, E. Levantamento da estrutura horizontal de uma mata de araucária no primeiro planalto paranaense. Boletim de Pesquisa Florestal, Colombo, n. 4, p. 1-46, 1982.

17. Pereira, J. O.; Azevedo, J. L.; Petrini, O. Endophytic fungi of Stylosanthes: a preliminary study. Mycologia, New York, v. 85, n. 3, p. 362-364, 1993. 
18. Petrini, O. Taxonomy of endophytic fungi of aerial plant tissues. In: Fokkema, N. J.; Heuvel, L. van den (Ed.). Microbiology of the phyllosphere. Cambridge: University Press, 1986, p. 175-87.

19. Petrini, O. Fungal endophytic of tree leaves. In: ANDREWA, J.; HIRANO, S. S. (Ed.). Microbial ecology of leaves. Viena: Spring Verlag, 1991, p. 179-197.

20. Rossman, A. Y.; Palm, M. E.; Spielman, L. J. A literature guide for the identification of plant pathogenic fungi. Saint Paul: APS, 1987. $252 \mathrm{p}$

21. Sen, R.; Hietala, A. M.; Zelmer, C. D. Common anastomosis and internal transcribed spacer RFLP grouping in binucleate Rhizoctonia isolates representing root endophytes of Pinus sylvestris,
Ceratorhiza spp. from orchid mycorrhizas and phytopathogenic anastomosis group. New Phytologist, Oxford, v. 144, n. 2, p. 331-341, 1999

22. Shimizu, J.Y. Pínus na silvicultura brasileira. Revista Madeira, Curitiba, edição especial, p.22-28, 2004.

23. Silva, F.A.S. The ASSISTAT Software statistical assistance. In: International Conference on Computers in Agriculture. American Society of Agricultural Engineers,v.6, p.294-298, 1996.

24. Spurr, H.W.; Welty, R.E. Characterization of endophytic fungi in healthy leaves of Nicotiana spp. Phytopathology, Saint Paul, v. 65, p.417-422, 1975. 